\title{
A case of an infant suspected as IMAGE syndrome who were finally diagnosed with MIRAGE syndrome by targeted Mendelian exome sequencing
}

\author{
Yoon-Myung Kim¹, Go Hun Seo ${ }^{1}$, Gu-Hwan Kim², Jung Min Ko ${ }^{3}$, Jin-Ho Choi ${ }^{1}$ and Han-Wook Yoo ${ }^{1 *}$ (D
}

\begin{abstract}
Background: Adrenal hypoplasia is a rare congenital disorder, which can be classified into a non-syndromic form, without extra-adrenal features, and a syndromic form, with such features. Despite biochemical and molecular genetic evaluation, etiologic diagnosis cannot be performed in many patients with adrenal hypoplasia.

Case presentation: The patient in this case was a boy born at 31 weeks of gestation with a weight of $882 \mathrm{~g}(<3 \mathrm{rd}$ percentile) to non-consanguineous parents. Genital examination showed micropenis and bilateral cryptorchidism. On the third day of life, he manifested hypotension with high urine output, hyponatremia, hyperkalemia, hypernatriuria, high plasma adrenocorticotropic hormone level, and high plasma renin activity, suggesting acute adrenal insufficiency. The serum 17a-hydroxyprogesterone level was normal. Adrenal insufficiency improved following administration of hydrocortisone and 9a-fludrocortisone, but the patient died of recurrent infection at 4 months of age. He was suspected as IMAGE (Intrauterine growth restriction, Metaphyseal dysplasia, Adrenal hypoplasia congenita, and Genital anomalies) syndrome. However, no mutation in CDKN1C was identified. Targeted exome sequencing using the TruSight One Sequencing Panel (Illumina) identified a heterozygous mutation of c.2944C > T (p.R982C) in exon 3 in SAMD9.

Conclusion: This report describes the first Korean case of MIRAGE syndrome. The patient presented with severe primary adrenal insufficiency, intrauterine growth retardation, and recurrent infection. SAMD9 mutation should be considered in patients who present with adrenal hypoplasia and extra-adrenal phenotypes.
\end{abstract}

Keywords: Congenital adrenal hypoplasia, SAMD9, MIRAGE syndrome

\section{Background}

Major etiologies of adrenal insufficiency in children include impaired steroidogenesis, adrenal hypoplasia, familial glucocorticoid deficiency (FGD), FGD-like disorders, and adrenal destruction $[1,2]$. Congenital adrenal hyperplasia accounts for $80 \%$ of the causes of pediatric adrenal insufficiency [1]. Recent advances in molecular genetic technologies have enabled identification of a variety of rare causative genes in patients with primary adrenal insufficiency $[2,3]$. However, $20 \%-60 \%$ of patients with primary adrenal insufficiency remain genetically

\footnotetext{
* Correspondence: hwyoo@amc.seoul.kr

'Department of Pediatrics, Asan Medical Center Children's Hospital,

University of Ulsan College of Medicine, 88, Olympic-ro 43-gil, Songpa-Gu,

Seoul 05505, South Korea

Full list of author information is available at the end of the article
}

undiagnosed [2, 4]. Causative genes for primary adrenal hypoplasia include $N R O B 1$ and $N R 5 A 1$, which play a key role in human adrenal development $[5,6]$, and CDKN1C, which is known to cause IMAGE (Intrauterine growth restriction, Metaphyseal dysplasia, Adrenal hypoplasia congenita, and Genital anomalies) syndrome [7, 8]. Mutations in MC2R, MRAP, NNT, TXNRD2, and $A A A S$ are related to adrenal hypoplasia as part of an adrenocorticotropic hormone (ACTH) resistance syndrome [1]. Adrenal hypoplasia occurs secondarily to defects in transcription factors involved in pituitary development, such as HESX1, LHX4, and SOX3 [9], and rare syndromes such as Meckel-Gruber syndrome, PenaShokeir syndrome, hydrolethalus syndrome, GallowayMowat syndrome, and Pallister-Hall syndrome [3]. 
In 2016, mutations in $S A M D 9$ were identified in patients with adrenal hypoplasia with extra-adrenal features such as intrauterine growth restriction, recurrent infections, gonadal and bone marrow failure, a condition designated as MIRAGE (Myelodysplasia, Infection, Restriction of growth, Adrenal hypoplasia, Genital phenotypes, and Enteropathy) syndrome [10]. To date, a total of 21 patients with the syndrome, with 16 different mutations, have been reported [10-12].

It is difficult to make a correct diagnosis in patients with syndromic adrenal hypoplasia owing to the diverse genetic etiologies and overlapping clinical and biochemical features. The present report describes a patient with MIRAGE syndrome who presented with intrauterine growth retardation, adrenal insufficiency, and recurrent infection and had been initially suspected as having IMAGE syndrome.

\section{Case presentation}

The patient in this case was the first child born to nonconsanguineous parents with no family history of adrenal insufficiency. He was born at 31 weeks of gestation by Cesarean section, owing to severe oligohydramnios and fetal heart rate variability. At birth, the patient had symmetric intrauterine growth retardation with a weight of $882 \mathrm{~g}$ ( $<3$ rd percentile), a length of $35 \mathrm{~cm}$ ( $<3$ rd percentile), and a head circumference of $24 \mathrm{~cm}(<3 \mathrm{rd}$ percentile). On physical examination, profound skin hyperpigmentation, frontal bossing, low-set ears, bilateral cryptorchidism, and micropenis were noted.

The patient underwent mechanical ventilation immediately after birth owing to respiratory difficulty. Indomethacin was used on the sixth day of life to treat patent ductus arteriosus with pulmonary edema, and closure was eventually achieved. Three days after birth, the patient manifested hypotension, polyuria $(8.1 \mathrm{~mL} / \mathrm{kg} / \mathrm{h})$, hyponatremia $(128 \mathrm{mmol} / \mathrm{L})$, hyperkalemia $(6.0 \mathrm{mmol} / \mathrm{L})$, hypernatriuria $(104 \mathrm{mEq} / \mathrm{L})$, and an increased fractional excretion of sodium (6.2\%). Plasma ACTH level was tremendously elevated to $4670 \mathrm{pg} / \mathrm{mL}$ (normal range, 10$60 \mathrm{pg} / \mathrm{mL}$ ), with plasma cortisol at $5.6 \mu \mathrm{g} / \mathrm{dL}$ (normal range, $2.5-9.1 \mu \mathrm{g} / \mathrm{dL}$ ), plasma renin activity at $217 \mathrm{ng} / \mathrm{mL} /$ h (normal range, $<2.8 \mathrm{ng} / \mathrm{mL} / \mathrm{h}$ ), and plasma aldosterone at $55.1 \mathrm{pg} / \mathrm{mL}$ (normal range $190-1410 \mathrm{pg} / \mathrm{mL}$ ), suggesting severe adrenal crisis. However, plasma 17 $\alpha$ hydroxyprogesterone level was $6.0 \mathrm{ng} / \mathrm{mL}$ (normal range at gestational age of 31 weeks, $1-172 \mathrm{ng} / \mathrm{mL}$ ). A stress dose of intravenous hydrocortisone $(95 \mathrm{mg} /$ $\mathrm{M}^{2} /$ day), fludrocortisone acetate $(0.02 \mathrm{mg} /$ day $)$, and sodium chloride $(8 \mathrm{mEq} / \mathrm{kg} /$ day $)$ were administered. Subsequently, the patient's serum electrolytes, ACTH level, and blood pressure normalized, and the skin hyperpigmentation also showed improvement. The plasma ACTH level decreased to $82.7 \mathrm{pg} / \mathrm{mL}$ after 1 week of therapy and was maintained between $20 \mathrm{pg} / \mathrm{mL}$ and $40 \mathrm{pg} /$ $\mathrm{mL}$ during the follow-up period. Abdominal ultrasonography revealed non-visualization of both adrenal glands and the right testis. The left testis was located in the patient's abdominal cavity, and a right inguinal hernia was observed. Brain ultrasonography was normal.

Mild thrombocytopenia, ranging from 70,000 to $150,000 / \mathrm{mm}^{3}$, and normocytic anemia, ranging from 6.4 to $10.8 \mathrm{~g} / \mathrm{dL}$, manifested during the first week of life. Thrombocytopenia and anemia resolved spontaneously 1 month after birth, with the counts maintained over $300,000 / \mathrm{mm}^{3}$ and $10 \mathrm{~g} / \mathrm{dL}$, respectively. Blood cultures were negative for bacteria, and there was no evidence of congenital infections including toxoplasmosis, rubella, cytomegalovirus (CMV), or herpes simplex virus. Serum IgM level was below $4.5 \mathrm{mg} / \mathrm{dL}$ (normal range, $7.3 \pm$ $3.3 \mathrm{mg} / \mathrm{dL}$ ). The thymic shadow was visible on chest radiography. At 1 month of age, an elevation in Creactive protein (CRP) up to $3 \mathrm{mg} / \mathrm{dL}$ and leukocytosis (white blood cell [WBC] count of $35,400 / \mathrm{mm}^{3}$ ) were observed. Intravenous antibiotics, including vancomycin and amikacin, were administered under the diagnosis of neonatal sepsis. Serratia marcescens (S. marcescens) $(50,000 / \mathrm{mL})$ and Enterococcus faecium $(>100,000 / \mathrm{mL})$ were cultured in urine. However, no bacteria were isolated in blood cultures or cerebrospinal fluid. Follow-up urine culture was clear after administration of antibiotics for 4 days; however, CRP and WBC count were still elevated to $2-3 \mathrm{mg} / \mathrm{dL}$ and $15,000-20,000 / \mathrm{mm}^{3}$, respectively. Two weeks later, the patient manifested apnea and decreased oxygen saturation, with diffuse haziness in both lungs on chest radiography. Despite administration of antibiotics including vancomycin, imipenem/cilastatin, and amphotericin B, pneumonia, and respiratory difficulty gradually worsened, ultimately requiring the resumption of mechanical ventilation. Urine CMV culture, blood CMV polymerase chain reaction, and blood CMV IgG and IgM tests were all positive. Blood and urine CMV cultures were converted to negative after 3 weeks of intravenous ganciclovir. After 3 weeks of mechanical ventilation, $S$. marcescens was identified from cultured endotracheal aspirates $(100,000,000 / \mathrm{mL})$ and urine $(80,000 / \mathrm{mL})$. Despite antibiotic treatment, pneumonia was aggravated, and $S$. marcescens was also identified in blood cultures when the patient was 4 months old. CRP and WBC count rose to $25.9 \mathrm{mg} / \mathrm{dL}$ and $32,100 / \mathrm{mm}^{3}$, respectively. The pneumonia and sepsis exacerbated and the patient died of septic shock at 4 months of age.

The patient's karyotype performed at age one month was 46, XY without any chromosomal structural abnormality. Under suspicion of X-linked adrenal hypoplasia congenita or IMAGE syndrome, genetic analysis was performed. However, no mutation was identified in the NROB1 or $C D K N 1 C$ genes by Sanger sequencing. Therefore, targeted 
exome sequencing was performed using genomic DNA extracted from peripheral blood leukocytes. Written informed consent was obtained for exome sequencing from all parents and the study was approved by the local ethics committee. The exome was captured using the Trusight One Panel (Illumina Inc., San Diego, CA, USA), which enriches a $12-\mathrm{Mb}$ region spanning 4813 genes, and was sequenced on the NextSeq platform (Illumina Inc.). The mean depth of coverage was $114 \times$ and approximately $98 \%$ of targeted bases were read more than $10 x$. Reads were aligned to the hg19 human reference genome. The result was identification of a heterozygous missense variant of c.2944C $>\mathrm{T}$ (p.R982C) in exon 3 in the SAMD9 gene, which was reported to be pathogenic with gain-of-function effect [11] (Fig. 1). This variant was not found in normative population databases including 1000Genomes browser (http://phase3browser.1000genomes.org/) and Exome Aggregation Consortium Browser (http://exac.broadinstitute.org/) and predicted to be damaging by in silico prediction programs, including PolyPhen-2 (http://genetics.bwh.harvard.edu/ pph2/; score of 0.616) and Sorting Intolerant From Tolerant (http://sift.jcvi.org/; score of 0). This mutation was confirmed by Sanger sequencing using custom-designed primers (Fig. 2). Genetic analysis of parents could not be performed to confirm the de novo nature of the variant because the parents' blood samples were not available.

\section{Discussion and conclusions}

This report describes a case of MIRAGE syndrome with a heterozygous missense mutation in $S A M D 9$ in a patient who was initially suspected as having IMAGE syndrome. Recent advances in molecular genetic technologies have enabled the identification of new causative genes in patients with primary adrenal insufficiency of unknown etiology, but some patients remain genetically undiagnosed. To avoid missing the diagnosis of this newly recognized disease, it is necessary to carefully examine the extra-adrenal features.

Common features of MIRAGE syndrome include recurrent invasive infection, restriction of growth, adrenal hypoplasia, and genital phenotypes $[10,11]$. Other clinical features are preterm delivery, respiratory distress syndrome, and frontal bossing [11]. Chronic diarrhea with colonic dilatation was observed in almost all patients in previous reports [10,11]. Clinical characteristics of patients with MIRAGE syndrome in previous studies and the present report are summarized in Table 1. In the case described here, the patient manifested no gastrointestinal symptoms or additional features such as cerebellar hypoplasia, hydrocephalus, or short phalanges.

Myelodysplastic syndrome with mosaic monosomy 7 or monosomy $7 \mathrm{q}$ by the loss of the other allele on chromosome 7 has been founded in as many as seven of 19 patients, suggesting a gain of survival advantage [10,11]. Secondary somatic loss-of-function mutations of SAMD9 have been identified in four of eight patients, and this type of mutation also seems to be part of a survival strategy [11]. More than half of the identified patients died before 2 years of age owing to invasive infection including sepsis, meningitis, and fungal infections $[10,11]$. Postmortem analysis of two patients revealed thymic hypoplasia with a decrease in the number of cortical lymphocytes [10]. Two patients with mosaic monosomy 7 or monosomy $7 \mathrm{q}$ who underwent bone marrow transplantation were alive at the time of the report [11]. Discovering the pathogenesis of recurrent invasive infection in patients with MIRAGE syndrome might help increase survival, considering that almost all patients in the studies to date have died as a result of infection $[10,11]$.

$S A M D 9$ protein products are involved in the endosome system and might influence the growth factor signal transduction pathway $[10,13,14]$, resulting in profound growth inhibition in in vitro analysis $[10,11]$. SAMD9 protein products contain a sterile alpha motif (SAM) domain near the $\mathrm{N}$-terminal region and a widely expressed putative protein interaction module involved in interactions with proteins, DNA, and RNA. [13, 15]. Several phenotypes of $S A M D 9$ disorders seem to be causally related to the wide expression of the $S A M D 9$ gene, including its expression in adrenal glands, colon, bone marrow, liver, immune system, lung, and testis $[11,16]$. Biallelic inactivating mutations in SAMD9 


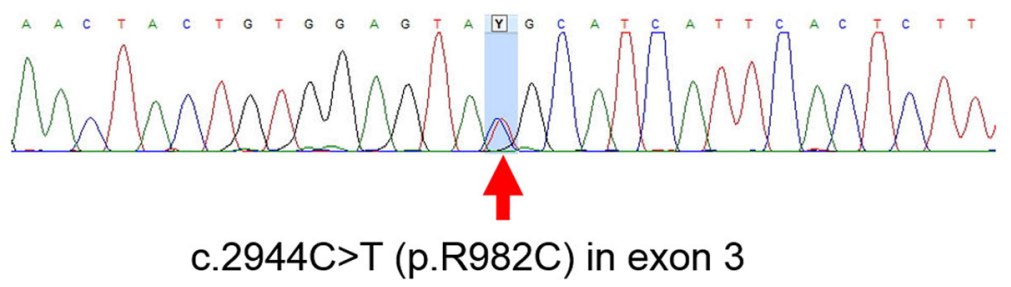

Fig. 2 Partial sequence of the SAMD9 gene. Sanger sequencing of SAMD9 identified a heterozygous mutation of c.2944C > T (p.R982C) in exon 3

cause normophosphatemic familial tumoral calcinosis, leading to the hereditary form of dystrophic calcification in the skin $[13,17,18]$. Downregulation of SAMD9 has also been found in mouse models with aggressive fibromatosis, breast cancer, colon cancer, and non-small cell lung cancer $[15,19]$. In contrast, overexpressing $S A M D 9$ mutations are presumed to be related to growth-restricting conditions due to the gain of function [10, 11].

The differential diagnosis of congenital adrenal hypoplasia includes X-linked adrenal hypoplasia congenita, NR5A1 mutation, Xp21 contiguous gene deletion syndrome, IMAGE syndrome, and ACTH insensitivity syndrome [1, 3]. Even within the same disease, the degree of clinical manifestations varies widely. Extra-adrenal features must be evaluated carefully to perform a diagnosis in patients with syndromic adrenal hypoplasia. IMAGE syndrome and MIRAGE syndrome share common features such as intrauterine growth restriction, adrenal hypoplasia, and genital anomalies, which could lead to confusion in diagnosis. Other characteristic features of IMAGE syndrome such as metaphyseal dysplasia, relative macrocephaly, and hypercalciuria have not

Table 1 Clinical characteristics of patients reported to have SAMD9 mutation and adrenal insufficiency

\begin{tabular}{|c|c|c|c|}
\hline & $\begin{array}{l}\text { Narumi et al. } \\
\text { (2016) [10] }\end{array}$ & $\begin{array}{l}\text { Buonocore et al. } \\
\text { (2017) [11] }\end{array}$ & $\begin{array}{l}\text { Present } \\
\text { study }\end{array}$ \\
\hline $\begin{array}{l}\text { Number of } \\
\text { patients }\end{array}$ & 11 & 8 & 1 \\
\hline Male:Female & $7: 4$ & $8: 0$ & Male \\
\hline IUGR & 11 & 8 & + \\
\hline Preterm delivery & NA & 8 (32 weeks) & + (31 weeks) \\
\hline $\begin{array}{l}\text { Adrenal } \\
\text { insufficiency }\end{array}$ & 11 & 7 & + \\
\hline $\begin{array}{l}\text { Ambiguous } \\
\text { genitalia }\end{array}$ & 7 & 8 & + \\
\hline $\begin{array}{l}\text { Monosomy } \\
7 \text { or } 7 q\end{array}$ & 2 & 5 & - \\
\hline Recurrent infection & 10 & 7 & + \\
\hline Age at death (years) & $\begin{array}{l}1.5 \pm 1.6 \\
\text { (range, 0.3-5) }\end{array}$ & $\begin{array}{l}0.6 \pm 0.6 \\
\text { (range, } 0-1.8)\end{array}$ & 0.3 \\
\hline Survival & 3 & 2 & - \\
\hline
\end{tabular}

IUGR intrauterine growth restriction, NA not assessed been reported in MIRAGE syndrome [7]. The presence of recurrent invasive infection or chronic diarrhea suggests MIRAGE syndrome [10, 11].

In conclusion, SAMD9 mutation should be considered in patients who present with adrenal hypoplasia and extra-adrenal phenotypes such as intrauterine growth restriction and recurrent infection. Further research is necessary to investigate this extremely rare cause of primary adrenal insufficiency with extra-adrenal features.

\section{Abbreviations}

AAAS: ACHALASIA-ADDISONIANISM-ALACRIMA SYNDROME; ACTH: Adrenocorticotropic hormone; CDKN1C: CYCLIN-DEPENDENT KINASE INHIBITOR 1C; CMV: Cytomegalovirus; CRP: C-reactive protein; FGD: Familial glucocorticoid deficiency; HESX1: HOMEOBOX GENE EXPRESSED IN ES CELLS; Ig: Immunoglobulin; IMAGE: Intrauterine growth restriction, Metaphyseal dysplasia, Adrenal hypoplasia congenita, and Genital anomalies; LHX4: LIM HOMEOBOX GENE 4; MC2R: MELANOCORTIN 2 RECEPTOR; MIRAGE: Myelodysplasia, Infection, Restriction of growth, Adrenal hypoplasia, Genital phenotypes, and Enteropathy; MRAP: MELANOCORTIN 2 RECEPTOR ACCESSORY PROTEIN; NNT: NICOTINAMIDE NUCLEOTIDE TRANSHYDROGENASE; NROB1: NUCLEAR RECEPTOR SUBFAMILY 0 , GROUP B, MEMBER 1; NR5A1: NUCLEAR RECEPTOR SUBFAMILY 5, GROUP A, MEMBER 1; SAMD9: STERILE ALPHA MOTIF DOMAIN-CONTAINING PROTEIN 9; SOX3: SRY-BOX 3; TXNRD2: THIOREDOXIN REDUCTASE 2; WBC: White blood cell

\section{Acknowledgements}

We gratefully acknowledge the kind cooperation and agreement of the patient's parents.

\section{Funding}

This work was supported the Post-Genome Technology Development Program (10053626, Development of Decision Making System for Emergency Prediction) funded by the Ministry of Trade, Industry and Energy (MOTIE, Korea).

\section{Availability of data and materials}

All data generated or analysed during this study are included in this published article.

\section{Authors' contributions}

YMK, GHS and JHC wrote the manuscript. YMK, GHK and GHS analyzed the data. YMK and JMK collected biological samples and information. GHK performed targeted Mendelian exome and Sanger sequencing. JHC and HWY designed the study. All authors contributed to, read, and approved the final version of the manuscript.

\section{Ethics approval and consent to participate}

This study was approved by the Institutional Review Board and Ethics Committee of Asan Medical Center. Written, informed consent to participate was obtained for all participants, or their guardians, before blood samples were drawn.

\section{Consent for publication}

Written consent was obtained from the parents of patient for the publication, including child's data. 


\section{Competing interests}

The authors declare that they have no competing interests.

\section{Publisher's Note}

Springer Nature remains neutral with regard to jurisdictional claims in published maps and institutional affiliations.

\section{Author details}

${ }^{1}$ Department of Pediatrics, Asan Medical Center Children's Hospital, University of Ulsan College of Medicine, 88, Olympic-ro 43-gil, Songpa-Gu, Seoul 05505, South Korea. ${ }^{2}$ Medical Genetics Center, Asan Medical Center Children's Hospital, University of Ulsan College of Medicine, Seoul, South Korea. ${ }^{3}$ Department of Pediatrics, Seoul National University Children's Hospital, Seoul, South Korea.

Received: 5 December 2017 Accepted: 23 February 2018

Published online: 05 March 2018

\section{References}

1. Bornstein SR, Allolio B, Arlt W, Barthel A, Don-Wauchope A, Hammer GD, et al. Diagnosis and treatment of primary adrenal insufficiency: an Endocrine Society clinical practice guideline. J Clin Endocrinol Metab. 2016;101:364-89.

2. Guran T, Buonocore F, Saka N, Ozbek MN, Aycan Z, Bereket A, et al. Rare causes of primary adrenal insufficiency: genetic and clinical characterization of a large Nationwide cohort. J Clin Endocrinol Metab. 2016;101:284-92.

3. Malikova J, Fluck CE. Novel insight into etiology, diagnosis and management of primary adrenal insufficiency. Horm Res Paediatr. 2014;82:145-57.

4. Chan LF, Campbell DC, Novoselova TV, Clark AJ, Metherell LA. Whole-exome sequencing in the differential diagnosis of primary adrenal insufficiency in children. Front Endocrinol (Lausanne). 2015;6:113.

5. Suntharalingham JP, Buonocore F, Duncan AJ, Achermann JC. DAX-1 (NROB1) and steroidogenic factor-1 (SF-1, NR5A1) in human disease. Best Pract Res Clin Endocrinol Metab. 2015;29:607-19.

6. El-Khairi R, Martinez-Aguayo A, Ferraz-de-Souza B, Lin L, Achermann JC. Role of DAX-1 (NROB1) and steroidogenic factor-1 (NR5A1) in human adrenal function. Endocr Dev. 2011:20:38-46.

7. Kato F, Hamajima T, Hasegawa T, Amano N, Horikawa R, Nishimura G, et al. IMAGe syndrome: clinical and genetic implications based on investigations in three Japanese patients. Clin Endocrinol. 2014;80:706-13.

8. Arboleda VA, Lee H, Parnaik R, Fleming A, Banerjee A, Ferraz-de-Souza B, et al. Mutations in the PCNA-binding domain of CDKN1C cause IMAGe syndrome. Nat Genet. 2012;44:788-92.

9. Ferraz-de-Souza B, Achermann JC. Disorders of adrenal development. Endocr Dev. 2008;13:19-32.

10. Narumi S, Amano N, Ishii T, Katsumata N, Muroya K, Adachi M, et al. SAMDg mutations cause a novel multisystem disorder, MIRAGE syndrome, and are associated with loss of chromosome 7. Nat Genet. 2016:48:792-7.

11. Buonocore F, Kuhnen P, Suntharalingham JP, Del Valle I, Digweed M, Stachelscheid $\mathrm{H}$, et al. Somatic mutations and progressive monosomy modify SAMD9-related phenotypes in humans. J Clin Invest. 2017;127:1700-13.

12. Shima H, Koehler K, Nomura $Y$, Sugimoto K, Satoh A, Ogata T, et al. Two patients with MIRAGE syndrome lacking haematological features: role of somatic second-site reversion SAMD9 mutations. J Med Genet. 2017; https://doi.org/10.1136/jmedgenet-2017-105020.

13. Hershkovitz D, Gross Y, Nahum S, Yehezkel S, Sarig O, Uitto J, et al. Functional characterization of SAMD9, a protein deficient in normophosphatemic familial tumoral calcinosis. J Invest Dermatol. 2011;131:662-9.

14. Nagamachi A, Matsui $H$, Asou H, Ozaki Y, Aki D, Kanai A, et al. Haploinsufficiency of SAMD9L, an endosome fusion facilitator, causes myeloid malignancies in mice mimicking human diseases with monosomy 7. Cancer Cell. 2013;24:305-17.

15. Li CF, MacDonald JR, Wei RY, Ray J, Lau K, Kandel C, et al. Human sterile alpha motif domain 9, a novel gene identified as down-regulated in aggressive fibromatosis, is absent in the mouse. BMC Genomics. 2007;8:92.

16. Uhlen M, Fagerberg L, Hallstrom BM, Lindskog C, Oksvold P, Mardinoglu A, et al. Proteomics. Tissue-based map of the human proteome. Science. 2015; 347:1260419.

17. Chefetz I, Ben Amitai D, Browning S, Skorecki K, Adir N, Thomas MG, et al. Normophosphatemic familial tumoral calcinosis is caused by deleterious mutations in SAMD9, encoding a TNF-alpha responsive protein. J Invest Dermatol. 2008;128:1423-9.
18. Topaz O, Indelman M, Chefetz I, Geiger D, Metzker A, Altschuler Y, et al. A deleterious mutation in SAMD9 causes normophosphatemic familial tumoral calcinosis. Am J Hum Genet. 2006;79:759-64.

19. Ma Q, Yu T, Ren YY, Gong T, Zhong DS. Overexpression of SAMD9 suppresses tumorigenesis and progression during non small cell lung cancer. Biochem Biophys Res Commun. 2014;454:157-61.

\section{Submit your next manuscript to BioMed Central and we will help you at every step:}

- We accept pre-submission inquiries

- Our selector tool helps you to find the most relevant journal

- We provide round the clock customer support

- Convenient online submission

- Thorough peer review

- Inclusion in PubMed and all major indexing services

- Maximum visibility for your research

Submit your manuscript at www.biomedcentral.com/submit
Biomed Central 